\title{
DINÂMICA DO CARBONO ORGÂNICO DE SOLOS SOB PASTAGENS EM CAMPOS DE MURUNDUS
}

\author{
Dynamics of soils organic carbon under pastures in fields of murundus
}

Fernando André Silva Santos ${ }^{1 *}$; Maria Aparecida Pereira Pierangeli²; Fernando Luiz Silva ${ }^{3}$; Milson Evaldo Serafim4; Juberto Babilônia de Sousa4; Edimar Barbosa de Oliveira ${ }^{5}$

\footnotetext{
${ }^{1}$ Doutorando; Programa de Pós-Graduação em Agronomia; Universidade Estadual de Maringá, Campus de Maringá (UEM); fernandoandre_agro2007@hotmail.com (*autor para correspondência)

2 Professora Doutora; Departamento de Zootecnia e Programa de Pós-Graduação em Ciências Ambientais; Universidade do Estado de Mato Grosso, Campus de Pontes e Lacerda (UNEMAT); mapp@unemat.br

${ }^{3}$ Mestre; Coordenação de Pesquisa e Extensão; Instituto Federal de Educação, Ciência e Tecnologia do Mato Grosso, Campus de Alta Floresta (IFMT); fernandoluiz_s@hotmail.com

${ }_{4}^{4}$ Professor Doutor; Departamento de Ensino; Instituto Federal de Educação, Ciência e Tecnologia do Mato Grosso; Campus de Cáceres (IFMT); milsonserafim@gmail.com; jubertobabilonia@yahoo.com.br

${ }_{5}^{5}$ Doutorando; Programa de Pós-Graduação em Ciência Animal; Universidade Federal de Mato Grosso, Campus Cuiabá (UFMT); edimarzoo@hotmail.com
}

Artigo enviado em 14/02/2017, aceito em 26/04/2017 e publicado em 07/07/2017.

RESUMO: Este trabalho objetivou avaliar, via fracionamento físico, a associação do carbono orgânico (CO) com frações granulométricas de solos de campos de murundus localizados na bacia hidrográfica do Rio Guaporé, sudoeste do Estado de Mato Grosso. As coletas das amostras de solo foram realizadas entre setembro e novembro em três diferentes áreas: pastagem nativa em uso, pastagem cultivada e área nativa sem uso. Em cada área foram abertas minitrincheiras de $0,50 \mathrm{~m} \times 0,50 \mathrm{~m} \times 0,40 \mathrm{~m}$ e coletadas amostras deformadas e indeformadas nas profundidades de 0,0 0,10, 0,10-0,20 e 0,20-0,30 m, três repetições em delineamento inteiramente casualizado. Foram determinados o teor de CO, o carbono particulado (COP), associado à fração areia e o carbono organo-mineral (COM), associado às frações argila + silte. Não foi verificado diferença entre os ambientes avaliados para as variáveis analisadas nas diferentes profundidades. Os maiores teores de COM foram observados na camada de 0,0-0,10 m, em todas as áreas. Conclui-se que o uso de pastagens naturais e a implantação de pastagens cultivadas, até o momento, não alteraram os teores de carbono do solo bem como suas associações com as frações granulométricas.

Palavras-Chave: áreas úmidas, uso da terra, matéria orgânica particulada

\begin{abstract}
This study aimed to evaluate, by physical fractionation, the association of organic carbon (OC) with granulometric fractions of soils of fields of murundus located at the Guaporé River hydrographic basin, southwest of the State of Mato Grosso. The sampling of soil were carried out between september and november 2011 in three different areas: native pastures in use, cultivated pastures and native areas without use. In each area were open minitrenches of $0,50 \mathrm{~m} \times 0,50 \mathrm{~m} \times 0,40 \mathrm{~m}$ and collected disturbed and undisturbed samples at the depths of $0,0-0,10,0,10$ 0,20 and $0,20-0,30 \mathrm{~m}$ in three replications in completely randomized design. Were determined the carbon content (CO) and particulate carbon (COP), associated with the sand fraction and the organo-mineral carbon (COM), associated with argil + silt fractions. Was not observed difference between the environments evaluated for the variables evaluated in different depth. The highest levels of COM were observed at the depth of 0,0-0,10 $\mathrm{m}$ in all areas. It is concluded that the use of native pastures and cultivated pastures, until now, did not alter the contents of soil carbon as well as their associations with the granulometric fractions.
\end{abstract}

Keywords - wetlands, land use, particulated organic matter 


\section{INTRODUÇÃO}

A importância da matéria orgânica do solo (MOS) para os diversos processos físicos, químicos e biológicos é amplamente reconhecida. A MOS desempenha diversas funções no ambiente, estando ligada a processos fundamentais como a ciclagem e retenção de nutrientes, agregação do solo e dinâmica da água, além de ser a fonte básica de energia para a atividade biológica (MACHADO, 2001; CARVALHO et al., 2010) e sua perda pode interferir drasticamente em vários processos, dificultando o desempenho das funções do solo, provocando desequilíbrios no sistema e, consequentemente, desencadeando o processo de degradação. Nesse contexto, o uso do solo para atividades agropecuárias frequentemente altera os teores de carbono do solo (MAIA et al., 2010; CARVALHO et al., 2010; SOUSA et al., 2015). Consequentemente, os principais constituintes da MOS, tais como o $\mathrm{CO}$ e N, são afetados (MAIA et al., 2010; SOUZA et al., 2009), podendo contribuir para as mudanças climáticas. No entanto, Carvalho et al. (2014) preconizam que práticas adequadas, como por exemplo, a integração lavourapecuária, são ferramentas estratégicas para a redução das emissões de gases do efeito estufa, em solos de Cerrado.

Segundo Pillon, Mielniczuk e Martin Neto (2002), do ponto de vista agronômico e ambiental, é importante que frações da MOS possam ser diretamente relacionadas a suas funções no solo, e nesse conjunto, a MOS pode ser dividida em uma fração lábil (ativa) e uma fração estável (humificada). Para esses autores, a primeira corresponde a substâncias de baixo peso molecular, provenientes de restos vegetais e animais, seus produtos primários de decomposição e biomassa microbiana, sendo bastante expressiva em solos de regiões temperadas. Já a fração estável é composta por substâncias húmicas e outras macromoléculas orgânicas resistentes à ação microbiana que se encontram no interior de agregados do solo. Dessa forma, para melhor entendimento da dinâmica da MOS tem sido usado tanto o fracionamento físico, quanto o químico (BARRETO et al., 2008; BARROS et al., 2012), sendo o fracionamento físico mais utilizado por alguns autores (CONCEIÇÃO et al., 2008; SALTON et al., 2011, COSER et al., 2012).

O fracionamento físico granulométrico é baseado no tamanho das partículas, utilizando-se o peneiramento e sedimentação em proveta, sendo separadas nas frações areia - matéria orgânica particulada (maior que $53 \mu \mathrm{m}$ ) e matéria orgânica ligada aos minerais silte $(2-53 \mu \mathrm{m})$ e argila $(0-2 \mu \mathrm{m})$ (ROSSI et al., 2012). A presença de partículas minerais nas frações pode complicar estimativas da matéria orgânica ao longo do tempo dentro dessas frações, sendo necessária a separação da matéria orgânica dentro de uma classe de tamanho especifico das partículas minerais (CAMBARDELLA; ELLIOTT, 1993).

Recentemente, em função de vários fatores, os estudos de MOS no solo, tem se baseado na quantificação dos teores de carbono (MAIA et al., 2010; CARVALHO et al., 2014). Assim, doravante esse trabalho usará o termo carbono do solo (CS) para designar os vários estudos envolvendo a MOS. Dessa forma, alguns trabalhos recentemente têm investigado qual a magnitude da alteração dos estoques de CS quando áreas nativas são convertidas para utilização agropecuária (RANGEL; SILVA, 2007; PORTUGAL et al., 2008; CARVALHO et al., 2010; SCHIAVO et al. (2011), SILVA et al. (2011); SOUSA et al., 2015; OLIVEIRA et al., 2017), pois o estoque de carbono pode ser indicativo de qualidade do solo. Além disso, o estudo das frações lábeis do CS pode fornecer informações sobre as alterações ocorridas em períodos curtos de utilização dessas áreas.

Mundialmente, diversas áreas úmidas são utilizadas para a produção de alimentos e entre essas áreas estão os campos de murundus, que são caracterizados como áreas de relevo plano, imperfeitamente drenadas e saturadas com água no período chuvoso, na qual inúmeros morrotes se encontram distribuídos regularmente (RESENDE et al., 2004; SANTOS et al., 2015). Devido às condições hidromórficas dessas áreas, em grande parte do ano, vários estudos mostram que a dinâmica da MOS pode ser completamente alterada, conforme mostram o trabalho de Sousa et al. (2015).

No estado de Mato Grosso, os campos de murundus são de ampla ocorrência (MARIMON et al., 2012; SANTOS et al., 2015) e, gradualmente estão sendo drenados e incorporados à atividade agrícola, tanto para plantação de grandes culturas (soja, milho, por exemplo), conforme pode ser observado quando se viaja para as regiões da bacia do rio Araguaia, entre outras localidades.

Na região sudoeste do Estado de Mato Grosso, os campos de murundus ocorrem na bacia hidrográfica do Rio Guaporé, e assumem importância econômica e social, ocupando grandes extensões de terra na região de fronteira entre Brasil e Bolívia. Na região essas áreas são utilizadas, principalmente, para pecuária extensiva de corte, como pastagem nativa. No entanto não é conhecida a magnitude das alterações ambientais decorrentes dessas atividades (SANTOS et al., 2015), sendo necessários estudos que consigam quantificar de modo mais rápido e preciso a qualidade dos solos dessas áreas, sendo a quantificação do CS, um dos indicadores 
mais recomendados para isso. Dessa forma, o objetivo deste trabalho foi avaliar os compartimentos de carbono orgânico do solo de campos de murundus utilizados com pastagens na bacia hidrográfica do rio Guaporé, sudoeste do Estado de Mato Grosso.

\section{MATERIAL E MÉTODOS}

O estudo foi realizado em campos de murundus localizados na bacia hidrográfica do rio Guaporé, região sudoeste do Estado de Mato Grosso, entre os municípios de Vila Bela da Santíssima Trindade e Pontes e Lacerda (Figura 1). Essas áreas anualmente são utilizadas como pastagens, de maneira intermitente (apenas no período de seca na região), estimando-se que esse manejo seja realizado há aproximadamente 20 anos.

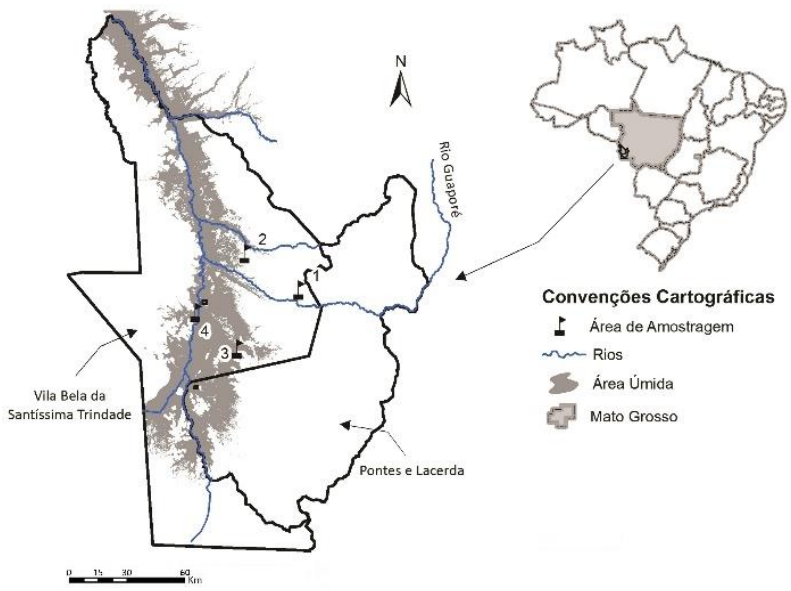

Figura 1. Localização da área do estudo e das áreas de amostragem dos solos (1, 2, 3 e 4) nos campos de murundus da bacia hidrográfica do rio Guaporé.

A região do estudo possui clima Tropical Continental, com características de Úmido a Sub-úmido, com pluviosidade de 1.200 a $1.500 \mathrm{~mm}$ anuais e constituem áreas planas, com altitudes em torno de 200 $\mathrm{m}$ elaboradas em sedimentos arenosos, siltico-arenosos e areno-conglomeráticos recentes. As baixas declividades, o modelado plano e as características edáficas dificultam o escoamento das águas, tornando essas áreas sujeitas a inundações periódicas ou permanentes. Os solos predominantes nessas áreas são Plintossolos álicos, recobertos por Savana Estépica e formações do contato Savana Arbórea Aberta/Savana Estépica (MOREIRA; VASCONCELOS, 2007). No entanto, nas áreas do estudo foram encontradas três Classes de solo: Plintossolo háplico distrófico típico; Cambissolo háplico distrófico plintossólico e Neossolo
Quartzarenico hidromórfico plintossólico, segundo Silva et al. (2014)

Foi utilizado o delineamento inteiramente casualizado, em esquema de parcela subdividida, com as áreas na parcela e as profundidades na sub parcela. As coletas das amostras de solo foram realizadas entre setembro e novembro de 2011, no fim do período de seca na região. $\mathrm{Na}$ grande área denominada Campos de Murundus foram selecionadas 4 subáreas nas seguintes coordenadas: (Ponto 1 - 1509'31" $50 \mathrm{~S}$ - 59॰33’28"67 O; Ponto 2 - 1502'16"19 S - 59 46'23"66 O; Ponto 3 $15^{\circ} 30^{\prime} 25^{\prime \prime} 30 \mathrm{~S}-59^{\circ} 41^{\prime} 48^{\prime \prime} 46$ O; e Ponto 4 - 15¹8'20"19 S 59 57'10"12 O). Em cada ponto de coleta (Figura 1) foram selecionados três ambientes representativos: área nativa sem uso (referência) (ANR), pastagem nativa em uso (PNU) e pastagem cultivada (PC). Todas as áreas se encontram saturadas com água em parte do ano (período chuvoso entre outubro e março). Em cada área foi aberta uma mini-trincheira de $0,50 \mathrm{~m} \times 0,50 \mathrm{~m} \times$ $0,40 \mathrm{~m}$ e coletadas amostras deformadas e indeformadas nas profundidades de $0,0-0,10,0,10-0,20$ e $0,20-0,30 \mathrm{~m}$. Totalizou-se nove tratamentos das combinações entre as áreas e profundidades $(3 \times 3)$, os quais foram coletados em quatro repetições, constituindo 36 amostras. Para cada amostra foram feitas triplicatas, perfazendo, portanto, 108 amostras no total, considerando todos os pontos de amostragem. As amostras foram imediatamente conduzidas ao laboratório para preparo e análises.

Os teores de carbono orgânico do solo (CO) foram determinados de acordo com metodologia preconizada por Embrapa (2011), por oxidação úmida com solução de dicromato de potássio em meio ácido. O fracionamento físico foi realizado segundo a metodologia de Cambardella e Elliott (1992) adaptada de Costa et al. (2004) e Rossi et al. (2012): foram pesados aproximadamente $20 \mathrm{~g}$ de solo (TFSA) adicionando-se $60 \mathrm{~mL}$ de solução solubilizante de hexametafosfato de sódio $\left(5 \mathrm{~g} \mathrm{~L}^{-1}\right)$. As amostras foram homogeneizadas por 16 horas em agitador horizontal em rotação média de $190 \mathrm{rpm}$. Após essa etapa, foi realizado o peneiramento úmido, utilizando-se peneira com malha de $53 \mu \mathrm{m}$. No material retido na peneira (fração areia) foi determinado o carbono orgânico particulado (COP), o qual consiste no $\mathrm{CO}$ associado à fração areia, enquanto na fração que passou a peneira (frações silte + argila) foi determinado o carbono organo-mineral (COM), o qual consiste no $\mathrm{CO}$ associado à fração argila + silte. $\mathrm{O}$ material que ficou retido na peneira foi transferido para placa de Petri e seco em estufa a $50^{\circ} \mathrm{C}$ até atingir peso constante. Após seco, o material foi moído em gral de porcelana e analisado o teor de CO segundo Embrapa (2011). O teor de COM foi obtido a partir da diferença entre o CO do 
solo e aquele do COP. Os valores de densidade utilizados no cálculo dos estoques de carbono foram determinados pelo método do anel volumétrico e a granulometria pelo método da pipeta conforme Embrapa (2011).

Para o cálculo dos estoques de carbono foi utilizado o método da camada equivalente, com a seguinte equação:

$$
E C O=\frac{C O \times D s \times E \times A}{F}
$$

Em que: ECO - estoque de carbono orgânico $\left(\mathrm{Mg} \mathrm{ha}^{-1}\right)$; $\mathrm{CO}$ - teor de carbono orgânico $\left(\mathrm{g} \mathrm{kg}^{-1}\right)$; Ds - densidade do solo $\left(\mathrm{Mg} \mathrm{m}^{-3}\right)$; E - espessura da camada de solo (m); A - unidade de área $\left(\mathrm{m}^{2}\right)$; e F - fator de conversão de $\mathrm{kg}$ para $\mathrm{Mg}(1.000)$.

Para padronização dos resultados, nos ambientes submetidos à intervenção antrópica (PNU e PC) foi adotado o valor de densidade do solo determinado na área natural sem uso (referência), de modo a evitar que a compactação do solo nos ambientes, decorrentes de pisoteio animal, adensamento natural, entre outros fatores, resultasse em maiores valores de estoque. Procedimento semelhante que tem sido adotado em outros trabalhos dessa natureza (CARDOSO et al., 2010; PULRONIK et al., 2009)

Os cálculos do índice de manejo do carbono (IMC) foram obtidos conforme a descrição de Rossi et al. (2012). Para a obtenção do IMC, foram calculados anteriormente o índice de estoque de carbono (IEC), a labilidade do carbono (L) e o índice de labilidade do carbono (IL). O IEC foi calculado a partir da razão entre o estoque de carbono com intervenção antrópica (PC ou PNU) e o estoque de carbono da área de referência. A labilidade foi calculada pela razão entre os estoques de carbono orgânico particulado (ECOP) e os estoques de carbono orgânico associado aos minerais (ECOM) e o índice de labilidade pela razão entre a $\mathrm{L}$ da área antropizada e a $\mathrm{L}$ da área de referência. Por fim, o IMC foi obtido multiplicando-se o IEC e o IL e este resultado por 100 conforme equação proposta por Blair, Lefroy e Lisle (1995):

$$
I M C=I E C \times I L \times 100
$$

A estimativa do IMC foi realizada considerando-se os valores médios de todas as profundidades, adotando-se para a área de referência $\mathrm{IMC}=100$
Os resultados obtidos foram submetidos ao teste de normalidade Kolmogorov Smirnov e homogeneidade de variância pelo teste de Bartlett. Quando atendidos estes pressupostos, foi utilizada a análise de variância e teste de comparação de médias de Tukey $(p=0,05)$. $\mathrm{Na}$ ausência de normalidade as variáveis foram submetidas ao teste de Kruskal Wallis e comparação múltipla pelo teste de Dunn $(p=0,05)$ utilizando o software XLSTAT (ADDINSOFT, 2013).

\section{RESULTADOS E DISCUSSÃO}

Os teores de areia, silte e argila nos diferentes ambientes e nas diferentes profundidades são apresentados na Tabela 1 . Tanto nos ambientes como nas profundidades os teores de argila foram diferentes considerando o efeito isolado de cada fator estudado. $\mathrm{O}$ teor de argila diferiu e foi menor no ambiente de pastagem nativa em uso comparado aos demais ambientes, os quais não diferiam entre si. Para as diferentes profundidades, foi verificada diferença para o teor de argila, que foi menor na profundidade de 0,0$0,10 \mathrm{~m}$, não havendo diferença entre as duas outras profundidades. Para os teores de areia e silte, não foram verificadas diferenças para ambientes e profundidades.

Verifica-se que em todas as áreas e profundidades amostradas, há elevados teores de areia, e, portanto, a classificação textural mais simplificada indica que estes solos são de textura média. De modo mais detalhado, os solos dos ambientes são classificados como franco argilo arenoso nas pastagens cultivadas e nas áreas nativas de referência e como franco arenosa nas pastagens nativas em uso. Quando se considera o gradiente de profundidade, todas as amostras possuem textura franco argilo arenosa.

Tabela 1. Granulometria do solo de campos de murundus na bacia hidrográfica do Rio Guaporé, sudoeste de Mato Grosso, Brasil.

\begin{tabular}{cccc}
\hline \multirow{2}{*}{ Ambiente(1) } & Argila & Silte & Areia \\
\cline { 2 - 4 } & & $\mathrm{g} \mathrm{kg}^{-1}$ \\
\hline ANR & \\
(2) & $262,07 \mathrm{a}$ & 177,87 & 560,06 \\
PC & $254,37 \mathrm{a}$ & 148,08 & 597,54 \\
PNU & $197,88 \mathrm{~b}$ & 182,29 & 619,82 \\
\hline Profundidade (m) & & $\mathrm{g} \mathrm{kg}^{-1}$ \\
\hline $0,0-0,10^{(2)}$ & $212,25 \mathrm{~b}$ & 159,33 & 628,42 \\
$0,10-0,20$ & $238,97 \mathrm{a}$ & 165,76 & 595,27 \\
$0,20-0,30$ & $263,10 \mathrm{a}$ & 183,16 & 553,74 \\
\hline
\end{tabular}

(1) $\mathrm{ANR}=$ área nativa de referência; $\mathrm{PC}=$ pastagem cultivada; PNU $=$ pastagem nativa em uso. (2)Médias seguidas de mesma letra na coluna, não diferem pelo teste de Dunn $(\mathrm{p}=0,05)$. 
Os teores médios de $\mathrm{CO}$ e de suas frações, nos diferentes ambientes e nas diferentes profundidades são apresentados na Tabela 2 . Em relação às profundidades não foi verificada diferença entre os ambientes avaliados para as variáveis analisadas. $\mathrm{Na}$ ANR os teores de $\mathrm{CO}$ diferiram entre as profundidades, sendo maiores na profundidade de 0,0-0,10 m (Tabela 2). Já na PNU os teores de $\mathrm{CO}$ foram maiores na profundidade de 0,0 $0,10 \mathrm{~m}$, diferindo das profundidades de 0,10-0,20 e 0,20$0,30 \mathrm{~m}$, que não apresentaram diferença entre si. $\mathrm{Na} \mathrm{PC}$, as profundidades de $0,0-0,10$ e $0,10-0,20$ m apresentaram os maiores valores de $\mathrm{CO}$, diferindo da profundidade de $0,20-0,30 \mathrm{~m}$.

Os maiores teores de $\mathrm{CO}$ na profundidade 0,0 0,20 m são resultantes do maior aporte de resíduos orgânicos na camada superficial do solo, conforme observado em outras literaturas (COSTA et al., 2009; RANGEL; SILVA, 2007). A maior quantidade de CO em superfície diz respeito à presença de gramíneas nos ambientes estudados, as quais incorporam tanto ou mais material orgânico ao solo quando comparado a outros tipos de cobertura vegetal (PULROLNIK et al., 2009) porque boa parte de seu sistema radicular está localizado na superfície do solo, aumentando dessa maneira a quantidade de carbono nas primeiras camadas do solo, assim observado em outras condições de solo e manejo, tal como Nunes et al. (2011) em sistemas de manejo e de estoque de carbono em Latossolo sob Cerrado.

Tabela 2. Valores médios de carbono orgânico (CO), carbono orgânico associado aos minerais (COM) e de carbono orgânico particulado (COP) de campos de murundus na bacia hidrográfica do rio Guaporé, sudoeste de Mato Grosso, Brasil.

\begin{tabular}{|c|c|c|c|}
\hline \multirow{3}{*}{ Ambientes $^{(1)}$} & \multicolumn{3}{|c|}{ Profundidade $(\mathrm{m})$} \\
\hline & $0,0-0,10$ & $0,10-0,20$ & $0,20-0,30$ \\
\hline & \multicolumn{3}{|c|}{$\mathrm{CO}\left(\mathrm{g} \mathrm{kg}^{-1} \mathrm{solo}\right)$} \\
\hline $\operatorname{ANR}^{(3)}$ & $15,17 \mathrm{aA}$ & $9,72 \mathrm{bA}$ & 6,61 cA \\
\hline $\mathrm{PC}(3)$ & $14,65 \mathrm{aA}$ & 8,6 aA & $6,75 \mathrm{bA}$ \\
\hline \multirow[t]{2}{*}{$\mathrm{PNU}(2)$} & $11,45 \mathrm{aA}$ & $7,92 \mathrm{bA}$ & $5,55 \mathrm{bA}$ \\
\hline & \multicolumn{3}{|c|}{ COM (g kg-1 solo) } \\
\hline ANR (2) & $5,42 \mathrm{aA}$ & $2,31 \mathrm{bA}$ & $1,94 \mathrm{bA}$ \\
\hline $\mathrm{PC}(3)$ & 4,85 aA & $2,6 \mathrm{abA}$ & $1,71 \mathrm{bA}$ \\
\hline \multirow[t]{2}{*}{$\mathrm{PNU}(2)$} & 3,66 aA & $2,1 \mathrm{abA}$ & $1,53 \mathrm{bA}$ \\
\hline & \multicolumn{3}{|c|}{$\mathrm{COP}\left(\mathrm{g} \mathrm{kg}^{-1}\right.$ solo $)$} \\
\hline $\mathrm{ANR}^{(3)}$ & $9,74 \mathrm{aA}$ & $7,41 \mathrm{aA}$ & $4,66 \mathrm{aA}$ \\
\hline $\mathrm{PC}(3)$ & $9,8 \mathrm{aA}$ & $6,00 \mathrm{aA}$ & $5,04 \mathrm{aA}$ \\
\hline $\mathrm{PNU}^{(2)}$ & $7,79 \mathrm{aA}$ & 6,39 abA & $3,45 \mathrm{bA}$ \\
\hline $\begin{array}{l}\text { (1) ANR = área n } \\
\text { pastagem nativa } \\
\text { na linha e maiú } \\
(\mathrm{p}=0,05) \text {. }{ }^{(3)} \text { Méd } \\
\text { maiúsculas na co }\end{array}$ & eferência; 1 & $\begin{array}{l}\text { pastagem } \\
\text { as de mesm } \\
\text { diferem pe } \\
\text { letra, min }\end{array}$ & $\begin{array}{l}\text { ltivada; PNU } \\
\text { etra, minúscul } \\
\text { teste de Tuk } \\
\text { ulas na linha } \\
(\mathrm{p}=0,05) \text {. }\end{array}$ \\
\hline
\end{tabular}

Outros estudos em áreas úmidas mostraram que o uso antrópico dessas áreas reduziu os teores de CO (SOUSA et al., 2011), mesmo em períodos curtos de utilização (em torno de 5 anos nas áreas antropizadas) (WANTZEN et al., 2012), diferentemente do observado no presente estudo, em que os ambientes em uso não diferiram do natural, até o presente momento. Essas áreas úmidas podem ser também importantes armazenadoras de carbono no solo, apesar de os teores de CO dessas áreas não serem mais elevados daqueles onde os manejos aplicados reduzem o carbono do solo (D'ANDRÉA et al., 2004; MATOSO et al., 2012).

Os valores de COM na ANR foram maiores na profundidade de 0,0-0,10 $\mathrm{m}$, diferindo das demais profundidades $(0,10-0,20$ e $0,20-0,30 \mathrm{~m})$, que não apresentaram diferença entre si. Para os valores de COP, não houve diferença entre as profundidades. Os valores de COM no ambiente PNU foram maiores na profundidade de 0,0-0,10 $\mathrm{m}$ e menor na profundidade de 0,20-0,30 m. Para os valores de COP não houve diferença entre as profundidades avaliadas nesse ambiente. No ambiente PC o COM apresentou a mesma tendência observada em PNU para as profundidades analisadas, e para os valores de COP, as profundidades de 0,0-0,10 e de 0,20-0,30 $\mathrm{m}$ apresentaram o maior e o menor valor dessa variável, respectivamente (Tabela 2).

A fração COP comumente apontada como boa indicadora de alteração do uso do solo em outros estudos (FIGUEIREDO et al., 2010; LEITE et al., 2013), não detectou alterações decorrentes dos diferentes usos aplicados ao solo das áreas úmidas, discordando do que é reportado na maioria dos estudos. No entanto, Sousa et al. (2015) verificaram que o COP foi menor em áreas úmidas (veredas do bioma Cerrado) sem uso antrópico. O COP, fração associada a fração areia, pode indicar alterações decorrentes de diferentes usos do solo, mesmo em condições nas quais há predominância de argila no solo. Bayer et al. (2004), avaliando o armazenamento de carbono em frações lábeis da matéria orgânica de um Latossolo Vermelho de textura muito argilosa sob plantio direto, verificaram que o acúmulo de carbono no solo ocorreu na forma de COP. Os autores também afirmam que o acúmulo de CO na fração lábil da MOS implica que alguns sistemas e o aporte de resíduos devam ser mantidos continuamente, pois a sua interrupção pode resultar num fluxo líquido de carbono para a atmosfera.

Dentre as frações do CO, o predomínio de COP é um ponto negativo, pois denota que a maior parte do CO das áreas úmidas do presente estudo é pouco estável e com maior taxa de decomposição, pouco contribuindo para manutenção da qualidade do solo (ARAÚJO; GOEDERT; LACERDA, 2007). 
Menor quantidade de COM é indicativo de que a maior parte do carbono dos solos dessas áreas úmidas encontra-se pouco associado à argila + silte, as quais mesmo em baixa quantidade são capazes, em especial as argilas, de favorecer a interação entre a fração mineral e orgânica, formando complexos estáveis, não alterados facilmente pelo manejo.

Para o ECO, houve a mesma tendência obtida na análise dos teores de CO feita anteriormente, no entanto entre ambientes houve diferença na profundidade de 0,0-0,10 $\mathrm{m}$, onde o ambiente ANR possui o maior valor de ECO, se diferenciando da PNU e não diferindo da PC (Tabela 3 ). Em relação às profundidades nos ambientes, para todos os maiores valores de ECO estão na profundidade de 0,0-0,10 m. Para os ambientes de ANR e PC, as profundidades de 0,10-0,20 e 0,20-0,30 $\mathrm{m}$ não foram diferentes entre si.

Os valores do estoque de carbono na fração associada aos minerais (ECOM) não diferiram entre ambientes nas diferentes profundidades (Tabela 3). Os valores de ECOM foram significativos apenas no ambiente de PNU no qual a profundidade de 0,0-0,10 m apresenta maior ECOM. Os resultados de estoque de carbono particulado (ECOP) foram diferentes entre ambientes e entre profundidades. Entre os ambientes, houve diferença apenas na profundidade de $0,10-0,20 \mathrm{~m}$, onde as pastagens cultivadas têm o menor valor de ECOP, e os demais ambientes diferiram desse ambiente e não diferiram entre si. Para as profundidades nos ambientes, as pastagens cultivadas e as áreas nativas de referência têm os maiores valores de ECOP na profundidade de $0,0-0,10 \mathrm{~m}$ e para o ambiente PNU, os maiores estoques estão nas profundidades de $0,0-0,10 \mathrm{e}$ 0,10-0,20 m (Tabela 3).
Tabela 3. Valores médios de estoque de carbono orgânico (ECO), estoque de carbono orgânico associado aos minerais (ECOM) e de estoque de carbono orgânico particulado (ECOP) de campos de murundus na bacia hidrográfica do Rio Guaporé, sudoeste de Mato Grosso, Brasil.

\begin{tabular}{cccc}
\hline \multirow{3}{*}{ Ambientes $^{(1)}$} & \multicolumn{3}{c}{ Profundidade $(\mathrm{m})$} \\
\cline { 2 - 4 } & $0,0-0,10$ & $0,10-0,20$ & $0,20-0,30$ \\
\cline { 2 - 4 } & \multicolumn{3}{c}{$\mathrm{ECO}\left(\mathrm{Mg} \mathrm{ha}^{-1}\right)$} \\
\hline $\mathrm{ANR}^{(2)}$ & $23,14 \mathrm{aA}$ & $15,78 \mathrm{bA}$ & $10,69 \mathrm{bA}$ \\
$\mathrm{PC}^{(2)}$ & $22,59 \mathrm{aAB}$ & $14,07 \mathrm{bA}$ & $10,91 \mathrm{bA}$ \\
$\mathrm{PNU}^{(2)}$ & $17,71 \mathrm{aB}$ & $12,97 \mathrm{bA}$ & $8,95 \mathrm{cA}$ \\
\hline \multicolumn{3}{c}{$\mathrm{ECOM}\left(\mathrm{Mg} \mathrm{ha}^{-1}\right)$} \\
\hline $\mathrm{ANR}^{(2)}$ & $8,21 \mathrm{aA}$ & $3,66 \mathrm{aA}$ \\
$\mathrm{PC}^{(2)}$ & $7,39 \mathrm{aA}$ & $4,23 \mathrm{aA}$ & $2,12 \mathrm{aA}$ \\
$\mathrm{PNU}^{(2)}$ & $5,6 \mathrm{aA}$ & $3,34 \mathrm{bA}$ & $2,45 \mathrm{bA}$ \\
\hline \multicolumn{3}{c}{$\mathrm{ECOP}\left(\mathrm{Mg} \mathrm{ha}^{-1}\right)$} \\
\hline $\mathrm{ANR}^{(2)}$ & $14,92 \mathrm{aA}$ & $12,12 \mathrm{bA}$ \\
$\mathrm{PC}^{(2)}$ & $15,2 \mathrm{aA}$ & $9,84 \mathrm{bB}$ & $7,57 \mathrm{bA}$ \\
$\mathrm{PNU}^{(2)}$ & $12,11 \mathrm{aA}$ & $10,51 \mathrm{aA}$ & $5,61 \mathrm{bA}$ \\
\hline
\end{tabular}

(1) ANR = área nativa de referência; $\mathrm{PC}=$ pastagem cultivada; PNU $=$ pastagem nativa em uso. (2)Médias seguidas de mesma letra, minúsculas na linha e maiúsculas na coluna, não diferem pelo teste de Dunn $(\mathrm{p}=0,05)$.

É admissível supor que a ausência de alteração nos estoques de carbono entre os ambientes estudados esteja relacionada com a granulometria das amostras de solo (Tabela 1), que possuem elevados teores de areia e que não se diferem entre os ambientes estudados. Para a profundidades, o mesmo se aplica, pois conforme análise geral (Tabela 1), os teores de areia são elevados na camada de 0,0-0,10 m, influenciando as poucas alterações do ECOP nessa profundidade, que são confirmadas pelo baixo valor de correlação de Spearman $(\mathrm{p}=0,05)$ entre as duas variáveis $(\mathrm{r}=0,24 ; \mathrm{p}$ valor $=0,0107)$. Por haver predominância da fração areia, também são justificados os maiores valores para o estoque de carbono particulado quando comparados aos valores do estoque de carbono associado ao silte+argila.

Outro fator considerado para a ausência de diferença nos teores de $\mathrm{CO}$ e de suas frações entre os diferentes ambientes, bem como de seus estoques no solo, diz respeito às condições de umidade e de temperatura das áreas avaliadas, que apesar de permanecerem alagadas durante a estação chuvosa, durante a estação seca as condições ambientais podem acelerar o processo de decomposição do material orgânico adicionado ao solo, de modo análogo em todos os ambientes.

Em condições diferentes das existentes neste estudo, outros autores verificaram diferença entre os manejos aplicados aos solos no tocante ao comportamento das frações de carbono orgânico analisadas. Martins, Coringa e Weber (2009) em um 
Latossolo Vermelho Amarelo distrófico averiguaram que a distribuição do CO foi maior na fração grosseira $(>53 \mu \mathrm{m})$ para agrossistemas analisados, indicando menor presença de material orgânico associado ao silte e a argila, e a presença de resíduos mais recalcitrantes.

Os dados dos índices de estoque de carbono, índice de labilidade, labilidade e índice de manejo de carbono estão apresentados na Tabela 4, considerando apenas o efeito dos ambientes, pois para as profundidades não se constatou diferenças significativas nos teores de CO. Os índices de manejo de carbono e os demais índices para seu cálculo não sofreram alteração decorrente dos usos estabelecidos nos campos de murundus, e apenas a labilidade foi alterada entre os ambientes. $\mathrm{O}$ ambiente ANR possui maior labilidade quando comparado a PNU e a PC não difere dos demais ambientes.

Tabela 4. Índice de estoque de carbono (IEC), labilidade do carbono (L), índice de labilidade do carbono (IL) e índice de manejo do carbono (IMC) de campos de murundus na bacia hidrográfica do Rio Guaporé, sudoeste de Mato Grosso, Brasil.

\begin{tabular}{ccccc}
\hline Ambiente $^{(1)}$ & IEC & $\mathrm{L}^{(2)}$ & IL & IMC \\
\hline ANR & & $3,7 \mathrm{a}$ & 1,0 & 100,0 \\
PC & 1,0 & $1,5 \mathrm{ab}$ & 0,6 & 49,3 \\
PNU & 0,8 & $1,0 \mathrm{~b}$ & 0,6 & 49,7 \\
\hline
\end{tabular}

(1) ANR = área nativa de referência; $\mathrm{PC}=$ pastagem cultivada; $\mathrm{PNU}=$ pastagem nativa em uso. (2)Médias seguidas de mesma letra na coluna, não diferem pelo teste de Dunn $(\mathrm{p}=0,05)$.

Diferenças para a labilidade do carbono podem ser explicadas provavelmente pela estratificação vegetal desses ambientes e o manejo das pastagens realizado na região de estudo. Nas áreas nativas de referência, a ausência de práticas agrícolas permite que várias espécies vegetais depositem material orgânico, que é convertido a posteriori em carbono lábil (LEITE et al., 2013).

Para a PNU, a pressão de pastejo exercida combinada com a ausência de práticas que ajudem a manter o crescimento vigoroso das gramíneas nativas (ex: adubação) podem diminuir o aporte de material orgânico no solo. As pastagens cultivadas apresentam condição intermediaria para a labilidade supostamente pela presença de gramíneas melhoradas que aportam tanto ou mais material orgânico quanto nos demais ambientes. Alguns autores relatam que a presença de gramíneas perenes ajuda na manutenção do teor de carbono orgânico pelo processo de rizodeposição (CARNEIRO et al., 2009).

Mesmo na ausência de significância entre os índices de manejo de carbono (Tabela 4), e considerando o exposto por Blair et al. (1995) e Rossi et al. (2012), os valores obtidos denotam que os atuais usos aplicados aos campos de murundus não favorecem a conservação do carbono orgânico no solo. No entanto, essa interpretação deve ser relativizada haja vista que não houve diferença significativa entre os teores de CO entre os ambientes (Tabela 2).

O diagrama comparativo dos estoques de carbono orgânico nas áreas avaliadas, nas profundidades de $0,0-0,10,0,10-0,20$ e $0,20-0,30 \mathrm{~m}$ pode ser observado na Figura 2. Considerando o ECO (Tabela 3), sem fracionamento, numericamente constata-se que tanto a PNU quanto a PC resultam em declínio do carbono no solo, na camada superficial.

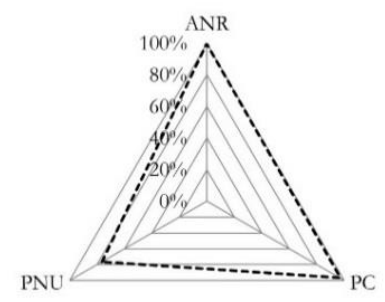

$0,0-0,10 \mathrm{~m}$

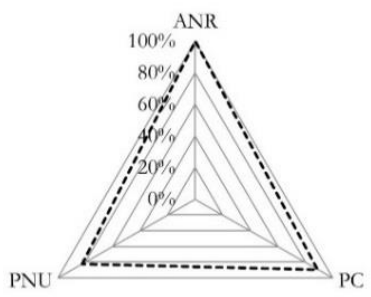

$0,10-0,20 \mathrm{~m}$

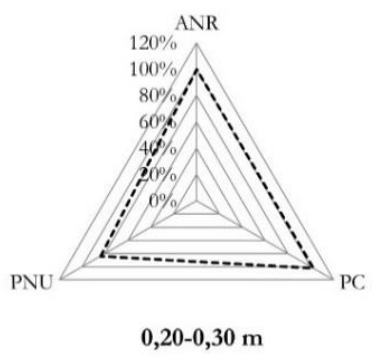

Figura 2. Diagrama comparativo para o estoque de carbono orgânico (ECO) em três profundidades nas diferentes áreas (ANR = área nativa de referência; $\mathrm{PC}=$ pastagem cultivada; $\mathrm{PNU}=$ pastagem nativa em uso) dos campos de murundus na bacia hidrográfica do Rio Guaporé, sudoeste de Mato Grosso, Brasil. 
Comparados à ANR, referencial de ambiente de estabilidade ecológica, observa-se que houve uma redução no ECO de 23,46 e 2,37\% para as PNU e PC, respectivamente, na profundidade de $0,0-0,10 \mathrm{~m}$. Para a segunda profundidade avaliada $(0,10-0,20 \mathrm{~m})$, as reduções no ECO, em comparação à área de referência, foram de $17,80 \%$ para as pastagens nativas em uso e $10,83 \%$ para as pastagens cultivadas. A última profundidade amostrada $(0,20-0,30 \mathrm{~m})$ também diferiu em relação ao valor de ECO, com reduções igual a 16,27 $\%$ para as áreas de pastagem nativas em uso e acréscimo de 2,05\% nas pastagens cultivadas, em relação à área de referência.

O diagrama mostrado na Figura 2 ilustra a tendência de que a intervenção antrópica nos ambientes úmidos não contribuiu para a manutenção do carbono no solo, mesmo após a conversão de áreas nativas em pastagens cultivadas, que poderia aumentar os teores de $\mathrm{CO}$, confirmando os resultados obtidos para o índice de manejo do carbono. Como pode ser observado nessa figura há uma diminuição no ECO menos acentuada para as pastagens cultivadas na primeira e segunda profundidades e acréscimo pouco pronunciado na última profundidade do solo, enquanto nas pastagens nativas em uso essa redução foi maior que $15 \%$ em todas as profundidades amostradas. Tendências semelhantes foram observados por outros autores a exemplo de Fernandes, Cerri e Fernandes (1999), D’Andréa et al. (2002) e Cardoso et al. (2010) quando se tem a substituição de áreas nativas por pastagens cultivadas.

Verifica-se que os valores de ECO nas áreas úmidas ora estudadas podem ou não serem mais elevados quando comparado àqueles obtidos por outros autores e em outras condições. D'Andréa et al. (2004) obtiveram valores médios de ECO de 37,98; 40,67; e $35,86 \mathrm{Mg} \mathrm{ha}^{-1}$ para Cerrado nativo, pastagem e plantio convencional, respectivamente. Cardoso et al. (2010) em áreas de Pantanal obtiveram valores variando de 17,81 a $24,42 \mathrm{Mg} \mathrm{ha}^{-1} \mathrm{em}$ ambientes de pastagem nativas; de 22 a 41,64 Mg ha-1 em pastagens cultivadas; e de 24,68 a $61,72 \mathrm{Mg} \mathrm{ha}{ }^{-1} \mathrm{em}$ áreas nativas (referência). Em ambientes de áreas úmidas era de se esperar maiores valores de ECO, em decorrência das condições anóxicas e dos processos anaeróbios, que são menos eficientes em termos de energia frente aos processos aeróbios e conferem maiores acúmulos de carbono quando comparados a outros ambientes.

É evidente que a adoção de diferentes usos da terra nas áreas de campos de murundus pode diminuir os teores de carbono do solo e mesmo a adoção de manejos tidos como mais sustentáveis não permitem a manutenção de teores de carbono elevados como os encontrados nas áreas nativas sem conversão. Souza et al. (2016) conduziram pesquisa sobre as alterações na matéria orgânica e agregados do solo após a conversão de campos de murundus em sistemas de plantio direto e constataram diminuição dos estoques iniciais de carbono do solo na implantação do novo uso da terra, havendo aumento dos estoques com o tempo de adoção do sistema, entretanto o plantio direto não fornece as quantidades originais obtidas nos campos de murundus, sendo necessários em torno de 34 anos para atingir os valores originais de carbono no solo, mantendo-se o manejo atual no qual foi realizado a quantificação dos estoques.

Independente do uso dos campos de murundus, é indispensável que sejam elaboradas políticas públicas visando a conscientização dos produtores que utilizam essas áreas bem como o fomento as pesquisas (SANTOS et al., 2014), visando adequar manejos de solo que reabilitem as funções ecológicas dos campos de murundus junto aos diversos usos da terra (grãos, carne, fibras, energia), dada a fragilidade desses campos e sua importância ecológica para processos como o sequestro de carbono (SOUZA et al., 2016).

\section{CONCLUSÕES}

O uso de pastagens naturais e a implantação de pastagens cultivadas não alteraram estatisticamente, até o momento, os teores de carbono orgânico do solo bem como de suas frações associadas a areia e ao silte + argila.

Houve predominância de materiais particulados suscetíveis à decomposição, indicando que essas áreas exigem manejos conservacionistas para armazenagem de carbono orgânico no solo.

\section{AGRADECIMENTOS}

À CAPES pela concessão da bolsa de estudo ao primeiro autor e à Rede Centro-Oeste de PósGraduação, Pesquisa e Inovação Tecnológica: rede ASA (Rede de estudos sociais, ambientais e de tecnologias para o sistema produtivo na região sudoeste de Mato Grosso) e ao CNPq pelo financiamento do projeto. 


\section{REFERÊNCIAS}

ADDINSOFT. XLSTAT-Pro, Core Statistical Software, 2013. Disponível em: <http://www.xlstat.com>. Acesso em: 26 fev. 2013.

ARAÚJO, R; GOEDERT, W.J.; LACERDA, M.P.C. Qualidade de um solo sob diferentes usos e sob Cerrado nativo. Revista Brasileira de Ciência do Solo, v. 31, n. 5, p. 1099-1108, 2007.

BARRETO, A.C.; FREIRE, M.B.G. DOS S.; NACIF, P.G.S.; ARAÚJO, Q.R. FREIRE, F.J.; INÁCIO, E. dos S.B. Fracionamento químico e físico do carbono orgânico total em um solo de mata submetido a diferentes usos. Revista Brasileira de Ciência do Solo, v. 32, n. 4, p. 1471-1478, 2008.

BARROS, K.R.M.; LIMA, H.V.; CANELLAS, L.P.; CLARA, K.D. Fracionamento químico da matéria orgânica e caracterização física de Terra Preta de Índio. Revista de Ciências Agrárias, v. 55, n. 1, p. 44-51, 2012.

BAYER, C.; MARTIN-NETO, L.; MIELNICZUK, J.; PAVINATO, A. Armazenamento de carbono em frações lábeis da matéria orgânica de um Latossolo Vermelho sob plantio direto. Pesquisa Agropecuária Brasileira, v. 39, n. 7, p. 677-683. 2004.

BLAIR, G. J.; LEFROY, D. B.; LISLE, L. Soil carbon fractions, based on their degree of oxidation, and the development of a carbon management index for agricultural systems. Australian Journal of Agricultural Research, v. 46, n. 7, p. 1459- 1466, 1995.

CAMBARDELLA, C.A.; ELLIOTTT, E.T. Methods for physical separation and characterization of soil organic matter fractions. Geoderma, v. 56, p. 449-457, 1993.

CAMBARDELLA, C.A.; ELLIOTT, E.T. Particulate soil organic matter changes across a grassland cultivation sequence. Soil Science Society of America Journal, v. 56, p. 777-783, 1992.

CARDOSO, E.L.; SILVA, M.L.N.; SILVA, C.A.; CURI, N.; FREITAS, D.A.F. de. Estoques de carbono e nitrogênio em solo sob florestas nativas e pastagens no bioma Pantanal. Pesquisa Agropecuária Brasileira, v. 45, n. 9, p. 1028-1035, 2010.

CARNEIRO, M.A.C.; SOUZA, E.D. de; REIS, E.F. dos; PEREIRA, H.S.; AZEVEDO, W.R. de. Atributos físicos, químicos e biológicos de solo de cerrado sob diferentes sistemas de uso e manejo. Revista Brasileira de Ciência do Solo, v. 33, n. 1, p. 147-157, 2009.

CARVALHO, J.L.N.; RAUCCI, G.S.; CERRI, C.E.P.; BERNOUX, M.; FEILG, B.J.; WRUCK, F.J.; CERRI, C.C. Impact of pasture, agriculture and crop-livestock systems on soil C stocks in Brazil. Soil and Tillage Research, v. 110, p. $175-186,2010$.

CARVALHO, J.L.N.; RAUCCI, G.S.; FRAZÃO, L.A.; CERRI, C.E.P.; CERRI, C.C. Crop-pasture rotation: A strategy to reduce soil greenhouse gas emissions in the Brazilian Cerrado. Agriculture, Ecosystems and Environment, v. 183, p. 167-175, 2014.

CONCEIÇÃO, P.C.; BOENI, M.; DIECKOW, J.; BAYER, C.; MIELNICZUK, J. Fracionamento densimétrico com politungstato de sódio no estudo da proteção física da matéria orgânica em solos. Revista Brasileira de Ciência do Solo, v. 32, n. 2, p. 541-549, 2008.

COSER, T.R.; FIGUEIREDO, C.C. de, RAMOS, M.L.G.; JANNUZZI, H.; MARCHÃO, R.L. Recuperação de carbono obtida por três métodos em frações da matéria orgânica de Latossolo, sob consórcio milho-forrageiras, no Cerrado. Bioscience Journal, v. 28, supl. 1, p. 91-97, 2012.

COSTA, F. de S.; BAYER, C.; ALBUQUERQUE, J.A. FONTOURA, S.M.V. Aumento de matéria orgânica num Latossolo bruno em plantio direto. Ciência Rural, v. 34, n. 2, p. 587-589, 2004.

COSTA, O.V.; CANTARUTTI, R.B.; FONTES, L.E.F.; COSTA, L.M.; NACIF, P.G. S.; FARIA, J.C. Estoque de carbono do solo sob pastagem em área de tabuleiro costeiro no sul da Bahia. Revista Brasileira de Ciência do Solo, v. 33, n. 5, p. 1137-1145, 2009.

D'ANDRÉA, A.F., SILVA, M.L.N.; CURI, N.; GUILHERME, L.R.G. Estoque de carbono e nitrogênio e formas de nitrogênio mineral em um solo submetido a diferentes sistemas de manejo. Pesquisa Agropecuária Brasileira, v. 39, n. 2, p. 179-186, 2004.

D'ANDRÉA, A.F.; SILVA, M.L.N.; CURI, N.; SIQUEIRA, J.O.; CARNEIRO, M.A.C. Atributos biológicos indicadores da qualidade do solo em sistemas de manejo na região do Cerrado no sul do estado de Goiás. Revista Brasileira de Ciência do Solo, v. 26, n. 4, 913923, 2002. 
EMPRESA BRASILEIRA DE PESQUISA AGROPECUÁRIA-EMBRAPA. Centro Nacional de Pesquisa de Solos. Manual de métodos de análises de solo. 2. ed. Rio de Janeiro: CNPS, 2011. 230 p.

FERNANDES, F.A.; CERRI, C.C.; FERNANDES, A.H.B.M. Alterações na matéria orgânica de um Podzol Hidromórfico pelo uso com pastagens cultivadas no Pantanal Mato-Grossense. Pesquisa Agropecuária Brasileira, v. 34, n. 10, 1943-1951, 1999.

FIGUEIREDO, C.C. de; RESCK, D.V.S; CARNEIRO, M.A.C. Labile and stable fractions of soil organic matter under management systems and native cerrado. Revista Brasileira de Ciência do Solo, v. 34, n. 3, p. 907-916, 2010.

LEITE, L.F.C.; ARRUDA, F.P. de; COSTA, C. do N.; FERREIRA, J. da S.; HOLANDA NETO, M.R. Qualidade química do solo e dinâmica de carbono sob monocultivo e consórcio de macaúba e pastagem. Revista Brasileira de Engenharia Agrícola e Ambiental, v. 17, n. 12, p. 1257-1263, 2013.

MACHADO, P.L.O. de A. Manejo da matéria orgânica de solos tropicais. Rio de Janeiro: Embrapa Solos, 2001. 20 p. (Documentos, 24)

MAIA, S.M.F.; OGLE, S.M.; CERRI, C.C. CERRI, C.E.P. Changes in soil organic carbon storage under different agricultural management systems in the Southwest Amazon Region of Brazil. Soil \& Tillage Research, v. 106, n. 2, p. 177-184, 2010.

MARIMON, B.S.; MARIMON-JUNIOR, B.H.; MEWS, H.A.; JANCOSKI, H.S.; FRANCZAK, D.D.; LIMA, H.S.; LENZA, E.; ROSSETE, A.N.; MORESCO, M.C. Florística dos campos de murundus do Pantanal do Araguaia, Mato Grosso, Brasil. Acta Botanica Brasilica, v. 26, n. 1, p. 181-196, 2012.

MARTINS, E. de L.; CORINGA, J.do E.S.; WEBER, O. L. dos S. Carbono orgânico nas frações granulométricas e substâncias húmicas de um Latossolo Vermelho Amarelo distrófico - LVAd sob diferentes agrossistemas. Acta Amazonica, v. 39, n. 3, p. 655-660, 2009.

MATOSO, S.C.G.; SILVA, A.N. da; FIORELLIPEREIRA, E.C.; COLLETA, Q.P.; MAIA, E. Frações de carbono e nitrogênio de um Latossolo VermelhoAmarelo distrófico sob diferentes usos na Amazônia brasileira. Acta Amazonica, v. 42, n. 2, p. 231-240, 2012.
MOREIRA, M.L.C.; VASCONCELOS, T.N.N. Mato Grosso: solos e paisagens. Cuiabá: Entrelinhas, 2007. 272p.

NUNES, R. de S.; LOPES, A.A. de C.; SOUSA, D.M.G. de; MENDES, I. de C. Sistemas de manejo e os estoques de carbono e nitrogênio em Latossolo de Cerrado com a sucessão soja-milho. Revista Brasileira de Ciência do Solo, v. 35, n. 4, p. 1407-1419, 2011.

OLIVEIRA, D.M. da S.; PAUSTIAN, K.; COTRUFO, M. F.; FIALLOS, A.R.; CERQUEIRA, A.G.; CERRI, C.E.P. Assessing labile organic carbon in soils undergoing land use change in Brazil: a comparison of approaches. Ecological Indicators, v. 72, p. 411-419, 2017.

PILLON, C.N.; MIELNICZUK, J.; MARTIN NETO, L. Dinâmica da matéria orgânica no ambiente. Pelotas: Embrapa Clima Temperado, 2002. 41 p. (Documentos, 105)

PORTUGAL, A.F.; JUCKSCH, I.; SCHAEFER, C.E.G.R.; WENDLING, B. Determinação de estoques totais de carbono e nitrogênio e suas frações em sistemas agrícolas implantados em Argissolo Vermelho-Amarelo. Revista Brasileira de Ciência do Solo, v. 32, n. 5, p. 20912100, 2008.

PULROLNIK, K.; BARROS, N.F.; SILVA, I.R.; NOVAIS, R.F.; BRANDANI, C.B. Estoques de carbono e nitrogênio em frações lábeis e estáveis da matéria orgânica de solos sob eucalipto, pastagem e cerrado no Vale do Jequitinhonha - MG. Revista Brasileira de Ciência do Solo, v. 33, n. 5, p. 1125-1136, 2009.

RANGEL, O.J.P.; SILVA, C.A. Estoques de carbono e nitrogênio e frações orgânicas de Latossolo submetido a diferentes sistemas de uso e manejo. Revista Brasileira de Ciência do Solo, v. 31, n. 6, p. 1609-1623, 2007.

RESENDE， I.L.M.; ARAÚJO， G.M.; OLIVEIRA, A.P.A.; OLIVEIRA, A.P.; ÁVILA JÚNIOR, R.S.A. A comunidade vegetal e as características abióticas de um campo de murundu em Uberlândia, MG. Acta Botanica Brasilica, v. 18, n. 1, p. 9-17, 2004.

ROSSI, C.Q.; PEREIRA, M.G.; GIÁCOMO, S.G.; BETTA, M.; POLIDORO, J.C. Frações orgânicas e índice de manejo de carbono do solo em Latossolo Vermelho sob plantio de soja no cerrado goiano. Revista Brasileira de Ciências Agrárias, v. 7, n. 2, p. 233-241, 2012.

SALTON, J.C.; MIELNICZUK, J.; BAYER, C.; FABRÍCIO, A.C; MACEDO, M.C.M.; BROCH, D.L. 
Teor e dinâmica do carbono no solo em sistemas de integração lavoura pecuária. Pesquisa Agropecuária Brasileira, v. 46, n. 10, p. 1349-1356, 2011.

SANTOS, F.A.S.; PIERANGELI, M.A.P.; SILVA, F.L.; SERAFIM, M.E.; SOUZA, C.A. de. Atributos químicos, físicos e estoque de cálcio, magnésio, potássio e fósforo em solos de campos de murundus no Brasil. Acta Amazonica, v. 45, n. 2, p. 101-110, 2015.

SANTOS, F.C.V.; FREITAS, I.C.; CUSTÓDIO FILHO, R.O.; CORRECHEL, V.; UCKER, F.E.; KEMERICH, P.D. da C. Uso e ocupação de microrrelevo de murundus no sudoeste de Goiás: uma abordagem sobre os aspectos físicos do solo. Revista Monografias Ambientais, v. 14, n. 1, p. 2988-2995, 2014.

SCHIAVO, J.A.; ROSSET, J.S.; PEREIRA, M.G.; SALTON, J.C. Índice de manejo de carbono e atributos químicos de Latossolo Vermelho sob diferentes sistemas de manejo. Pesquisa Agropecuária Brasileira, v. 46, n. 10, p. 1332-1338, 2011.

SILVA, E.F. da; LOURENTE, E.P.R.; MARCHETTI, M.E.; MERCANTE, F.M; FERREIRA, A.K.T.; FUJII, G.C. Frações lábeis e recalcitrantes da matéria orgânica em solos sob integração lavoura pecuária. Pesquisa Agropecuária Brasileira, v. 46, n. 10, p. 1321-1331, 2011.

SILVA, F.L.; PIERANGELI, M.A.P.; SANTOS, F.A.S.; SOUSA, J.B.; SERAFIM, M.E.; SOUZA, C.A. de. Caracterização pedológica de campos de murundus da bacia hidrográfica do Rio Guaporé no estado de Mato Grosso. Revista Geonorte, v. 10, n. 1, p. 51-58, 2014.

SOUSA, R.F. de; BRASIL, E.P.F.; FIGUEIREDO, C.C.; LEANDRO, W.M. Soil organic matter fractions in preserved and disturbed wetlands of the Cerrado biome. Revista Brasileira de Ciência do Solo, v. 39, n. 1, p. 222-231, 2015.

SOUSA, R.F. de; NASCIMENTO, J.L.; FERNANDES, E.P.; LEANDRO, W.M.; CAMPOS, A.B. Matéria orgânica e textura do solo em veredas conservadas e antropizadas no bioma Cerrado. Revista Brasileira de Engenharia Agrícola e Ambiental, v. 15, n. 8, p. 861-866, 2011

SOUZA, E.D. de; CARNEIRO, M.A.C.; PAULINO, H.B.; RIBEIRO, D.O.; BAYER, C.; ROTTA, L.A. Matéria orgânica e agregação do solo após conversão de "campos de murundus" em sistema plantio direto. Pesquisa Agropecuária Brasileira, v. 51, n. 9, p. 1194-1202, 2016.
SOUZA, E.D. de; COSTA, S.E.V.G. de A.; ANGHINONI, I.; CARVALHO, P.C. de F.; ANDRIGUETI, M.; CAIO, E. Estoque de carbono orgânico e de nitrogênio no solo em sistema de integração lavoura-pecuária em plantio direto, submetido a intensidades de pastejo. Revista Brasileira de Ciência do Solo, v. 33, n. 6, p. 1829-1836, 2009.

WANTZEN, K.M.; COUTO, E.G.; MUND, E.E.; AMORIM, R.S.S.; SIQUEIRA, A.; TIELBÖRGER, K.; SEIFAN, M. Soil carbon stocks instream-valleyecosystems in the Brazilian Cerrado agroscape. Agriculture, Ecosystems and Environment, v. 151, p. 70-79, 2012. 